\title{
Effect Of Direct Teaching Method On The Academic Achievement Of High And Low Achievers In The Subject Of English At The Secondary Level
}

\author{
Ishtiaq Hussain, Kohat University (KUST), Pakistan \\ Syed Nisar Hussain Hamdani, University of AJK, Pakistan \\ Uzma Quraishi, University of Management and Technology, Pakistan \\ Muhammad Zeeshan, University of Science and Technology, Pakistan
}

\begin{abstract}
The major objective of the study was to determine the role of the direct teaching method in the academic achievement of students in English at the secondary level. To achieve the said objective, the Solomon Four-Design pre-test/post-test equivalent group design was considered to be the most useful design for this study. The pre-test was used to measure the achievement. The pre-test was used only to equate the control and experimental groups. Thus, the Solomon four-group design was applied for treatment of the data. The experimental group was taught by the direct method, while the control group was taught by the traditional method for a period of six weeks. At the end of the treatment, a post-test was administered and scores of pre-test and post-test were served as data for the study. Applying t-test and analysis of variance tested to know the significance of difference between the scores of groups at 0.05 levels. After analyzing the secured data it was concluded that the direct teaching method was more effective as a teaching-learning technique for English compared to the traditional teaching method. Students in the direct teaching method outscored the students working in the traditional learning situation. Low achievers in the direct teaching showed significant superiority over low achievers learning English by the traditional method. Thus, direct teaching was found to be a more effective method for quality teaching of English to the low achievers as compared to the traditional method of teaching. High achievers, whether they were taught English by the direct or traditional method, retained learned material at the same rate. Low achievers who were taught English by the direct method retained more material as compared to low achievers taught by traditional method of teaching.
\end{abstract}

Keywords: teaching method, academic achievement, Solomon four-group, concluded, Direct Method, Traditional Method, Control group, quality teaching

\section{INTRODUCTION}

weet (1992) says, "Language is expression of ideas by means of which speech sounds are combined into
words, words are combined into sentences and combination of sentences gives answers to ideas and
thoughts".

Jesperson (1983) defines language as a "set of human habits" the purpose, which is to give expression to thoughts and feelings, and especially to impart them others.

English has always been rated high in Pakistan. In the past, it was treated as a compulsory subject from class 6th to onwards in public school system. It is being offered as a compulsory subject in English medium schools and is increasingly used as a medium of instruction. The private schools offer English as a subject from nursery 
classes. This means that students of public schools start studying English at the age of 11 years whereas the students of English medium schools start studying English at the age of 4 years.

Keeping in view the status of English, the Government of Pakistan has made a decision for introducing English as a compulsory subject from first level. The main objective of the study was to determine the role of direct teaching in the academic achievement of students English at Secondary level.

\section{REVIEW OF LITERATURE}

Every country has a national language, which is the means of expression of its thoughts, culture and covers the whole range of its social, cultural and official activities. In the present age of fast development in science and technology, there also arises the need of a foreign language to have an access to modern scientific knowledge and for international communication. English is a means of international communication since it has assumed the role of world language. The only language other than Urdu that understood to some extent in all part of Pakistan is English. It is reality that English has thrust its way in our life and thoughts. It is the language of legislative, law courts, commercial, markets, social circles, technology and economics because most of the information's are largely available in English. (Tanveer, 1998).

Learning a foreign language/second language is a complex process, as language is not just an act of putting meaningful words together. It needs a physical, intellectual and emotional response if we have to send or receive messages in it. Learning of a foreign language involves a new culture, a new way of thinking, feeling and acting. The learner has to be fluent, accurate and meaningful (Graff, 1985).

Abid (1979) selected two groups of the students of $10^{\text {th }}$ class. Their teacher's supplementary reading approach taught the experimental group for the five teaching periods per week containing thirty lessons. After the teaching of six weeks, the experimental group showed better results significant at 0.05 levels in reading comprehension than the control group. The increase in reading speed of experimental group was significantly better at 0.05 level in average students and development of interest in English language was also significantly better than that control group. It was concluded that overall performance of experimental group in all the reading aspects was significantly better than that of the control group; hence the supplementary reading method was suggested. It was better method for teaching of English reading comprehension; speed and interest .So the researcher recommended supplementary reading beside textbooks for effective reading of English.

Lionel (1985) reported that most textbooks used in reading were judged as inadequate. The main cause identified was that textbooks take a long time to produce; therefore, the selections they contain are often out of date by the time they reach the students. As a partial solution to the problem, the researcher suggested that the students should choose short readings for the class as their assignments.

\section{PROCEDURE}

In order to test the relative effectiveness of independent variable, i.e. an instructional paradigm (direct teaching), the choice of most suitable design for this experiment was the basic step. A number of factors affect the internal and external validity of experimental designs. Relevant to internal validity, there are eight different factors (these include history, maturation, testing, instrumentation, statistical regression, differential selection, experimental mortality, and selection maturation interaction). If these factors are not controlled in the design, they may produce adverse effects, which confound the effects of the independent variables as shown by the final test scores.

Whereas factors affecting internal validity operate on the scores derived from the dependent variables and, therefore, make the experiment poor as an experiment, factors affecting external validity operate upon the experimental treatments. Campbell and Stanley (1963) postulated four factors, which jeopardize external validity.

"The Solomon Four-Design pre-test post-test equivalent group design" was considered to be the most useful design for this study. 


\section{POPULATION}

The aim of this study was to investigate the relative effectiveness of direct teaching method in teaching English at secondary level. Therefore, students studying at secondary level were constituted the population of the study.

\section{DELIMITATION OF THE STUDY}

The study was delimited to English medium students of $9^{\text {th }}$ class.

\section{SAMPLE}

Two sections A and B of $9^{\text {th }}$ class of Federal Government boys secondary school Tarnol, Islamabad (Urdu medium) and two sections A and B of $9^{\text {th }}$ class of F.G. Model school for Boys I-9/4 Islamabad (English medium) were taken as sample of the study. Sample students of Federal Government boy's secondary school Naugazi Islamabad were further divided into two groups, i.e. the experimental and the control groups. Both the groups were equated on the basis of pre-test scores. Each group comprised 30 students.

\section{RESEARCH INSTRUMENTS}

In order to equate the control and the experimental groups, a teacher made pre-test was administered before the allocation of students to the experimental and the control groups. Immediately after the treatment was over, a teacher made post-test was administered to subjects of both the experimental and the control groups. The purpose of this test was to measure the achievement of the students constituting the sample. The researcher constructed these both tests after a through review of the techniques of test construction and related units of English

Both the pre-test and post-test were almost parallel with same difficulty level. The two chapters were taught before the start of experiment; also give a weight age of 25 percent in the both tests. Each test was composed of multiple choice test items, matching items pertaining to a combination of learning domains. These test items were based on the selected units of $9^{\text {th }}$ class English five units. These five units were taught during the experiment to both the experimental and the control groups, and were intended to measure the learning out comes..

\section{SELECTION AND TRAINING OF TEACHERS FOR EXPERIMENT}

One teacher from each Federal Government Boys secondary School Tarnol ,Islamabad (Urdu medium) and one teacher from F G Model school for Boys I-9/4, Islamabad (English medium) having equal qualification, equal teaching experience and considerably equal teaching potential were selected for teaching English to the control and the experimental groups. The teacher volunteered for teaching the experimental groups was provided two weeks training in Direct teaching i.e. one week for reading and one week for speech

\section{DATA COLLECTION}

During the experiment two different treatment patterns were applied. The control groups were provided with traditional routine situation in the classroom while experimental groups provided with direct teaching method as treatment. The experiment continued for six weeks. Soon after the treatment was over, post-test was administrated to measure the achievement of the sample subjects.

\section{ANALYSIS OF DATA}

Raw scores obtained from pre-test and post-tests were presented in tabular form for the purpose of interpretation. For the manipulation of data, the means, standard deviations, and differences of means were computed for each group. Significance of difference between the mean scores of both the experimental and control groups on the variable of pre-test and post test scores was tested at 0.05 levels by applying t-test. To examine the treatment affects for high and low levels of achievement of the two groups, The Solomon four group design $(2 \times 2$ 
analysis of variance) was applied. For this purpose, the students of two groups were divided into two halves, i.e. high achievers (above the mean score) and low achievers (below the mean score). This division was made on the basis of pre-test scores.

\section{RESULTS AND DISCUSSION}

This chapter is confined to the analysis and interpretation of data obtained from the pre-test and post-test. Significance of difference between the mean scores of experimental and control groups of English medium and Urdu medium on pre-test and post-test were found out by applying t-test, analysis of variance, and the Solomon four group design (analysis of variance).

\section{CONCLUSIONS}

In the light of statistical analysis and the findings of the study, the following conclusions were drawn.

1 On the whole, the direct teaching method is more effective as a teaching-learning technique for English in comparison to the traditional teaching method. Students in the direct teaching method outscored the students working in the traditional learning situation.

2 Low achievers in the direct teaching method showed significant superiority over low achievers learning English by the traditional method. Thus, direct teaching was found to be a more effective method for teaching English to the low achievers compared to the traditional method of teaching.

3 High achievers, whether they were taught English by the direct or traditional method, retained learned material at the same rate.

$4 \quad$ Low achievers taught English by the direct method retained more material as compared to low achievers taught by the traditional method of teaching. Therefore, direct teaching seemed to be a more effective teaching-learning technique for low achievers.

$5 \quad$ English textbooks mostly written for direct teaching were taught through the traditional method. These did not show good results because teachers were not conversant with the direct method.

\section{AUTHOR INFORMATION}

Dr Ishtiaq Hussain is working as Director in Institute of Education \& Research, Kohat University of Science \& Technology, Kohat, Pakistan. He did his Ph.D. at Arid \& Agriculture University Rawalpindi. He has 24 years teaching experience to his credit.

Dr. Syed Nisar Hussain Hamdani, did his Ph.D. in Economics. He is working as Dean Faculty of Arts, University of Azad Jammu \& Kashmir, Muzzafarabad, Pakistan.

Dr. Uzma Qurashi did her Ph.D. in Educational Management \& Planning at the University of Birmingham (UK). She joined the Faculty of Education and technology as Associate Professor in 2006 at the School of Social Sciences and Humanities

Muhammad Zeeshan, (MSCS) is a Ph.D. (Scholar) Department of Computer Science, University of Peshawar, Pakistan. He is working as Chairman of Institute of Information Technology, Kohat University of Science \& Technology, Kohat, Pakistan. He has about 6 years of teaching and administrative experience to his credit.

\section{REFERENCES}

1. Abid, A. K. (1979). A Study of the Effectiveness of Supplementary Reading Approach of Teaching English on Comprehension, Reading Periods and Interests of $10^{\text {th }}$ grade Level (unpublished) Ph. D. thesis, Institute of Education and Research, University of Punjab, Lahore, Pakistan. (pp. 190-205).

2. Agrammal, L. (1995). General Language Practices. Merrill Publishing, Company New York, USA. (pp. 32-34).

3. Arnold. L. (1942). Culture and Anarchy, Preface. London: Macmillan Co; Ltd, UK. (p. 98). 
4. Campbell, D. \& K. Stanley. (1963). Experimental and Quasi-Experimental Designs for Research on Teaching, in Handbook of Research on Teaching. Rand Mc Nelly and Company, Chicago, USA. (p. 175).

5. Collitzs, G. (1926). Approaches to English as Second Language and its Implementations Mc Graw-Hill New York, USA. (pp. 113-120).

6. Curran, C. (1982). Counseling-Learning: a Whole Person Model for Education. Mc Graw-Hill New York, USA. (pp. 213-224).

7. Farooq, R. A. (2001). Understanding Research in Education. University Institute of Education and Research University of Arid and Agriculture Rawalpindi, Pakistan.

8. Garret, H. E. (1997). Statistic in Psychology and Education. National Book Foundations, Islamabad, Pakistan. (pp. 191-192, 279-291).

9. Gay, L.R (2000). Educational Research Competencies for Analysis and Application. National Book Foundation, Islamabad, Pakistan. (pp.477-478,480-496).

10. Graff, W. (1985). Language and Learning Principles. . Longmans Green and Co LTD. London, UK. (pp. 60-67).

11. Huchan, D. (1985). A Practical Guide to the Teaching of English. The University of Chicago, Press, Ltd, USA. (pp. 13-14).

12. Jesperson, O. (1983). Language, Its Natures Development and Origion. $4^{\text {th }}$ edition New York, USA. (p. $143)$.

13. Lionel, M. (1985). Students Choice: Short Reading for the ESL, Classroom English Teaching Forum DC. Vol No-1 Washington, USA. (pp. 87-90).

14. Morris, K. (1988). Developing Second Language Skills, Second edition, Chapter-5 Chicago; and Mc Nelly College Publishing Company, USA. (pp. 44-50).

15. Petty, W. (1996). Second Report about the State of Knowledge about the Teaching of Vocabulary. National Council of Teachers Education, New York, USA. (pp. 54-56).

16. Richards, J. (1991). The Context of Language Teaching. Cambridge University Press, London, UK. (pp. 49, 520).

17. Rivers, W. (1981). Teaching Foreign Language Teaching. The University of Chicago, Press. Ltd, USA. (pp. 46-56).

18. Sweet, S. (1992). Language and the Study of Language, 4th edition. Merrill Publishing Company New York, USA. (p. 45).

19. Tanveer, M. (1998). Education and the Development of Muslim Nationalism in Pre-Partition India. University of California. (pp. 45-49). 
NOTES 